\title{
Exploring the Material-Induced Transcriptional Landscape of Osteoblasts on Bone Graft Materials
}

Citation for published version (APA):

Groen, N., Tahmasebi, N., Shimizu, F., Sano, Y., Kanda, T., Barbieri, D., Yuan, H., Habibovic, P., van Blitterswijk, C. A., \& de Boer, J. (2015). Exploring the Material-Induced Transcriptional Landscape of Osteoblasts on Bone Graft Materials. Advanced Healthcare Materials, 4(11), 1691-1700. https://doi.org/10.1002/adhm.201500171

Document status and date:

Published: 05/08/2015

DOI:

10.1002/adhm.201500171

Document Version:

Publisher's PDF, also known as Version of record

Document license:

Taverne

Please check the document version of this publication:

- A submitted manuscript is the version of the article upon submission and before peer-review. There can be important differences between the submitted version and the official published version of record.

People interested in the research are advised to contact the author for the final version of the publication, or visit the DOI to the publisher's website.

- The final author version and the galley proof are versions of the publication after peer review.

- The final published version features the final layout of the paper including the volume, issue and page numbers.

Link to publication

\footnotetext{
General rights Owners
rights.

- You may freely distribute the URL identifying the publication in the public portal. please follow below link for the End User Agreement:

www.umlib.nl/taverne-license

Take down policy

If you believe that this document breaches copyright please contact us at:

repository@maastrichtuniversity.nl

providing details and we will investigate your claim.
}

Copyright and moral rights for the publications made accessible in the public portal are retained by the authors and/or other copyright owners and it is a condition of accessing publications that users recognise and abide by the legal requirements associated with these

- Users may download and print one copy of any publication from the public portal for the purpose of private study or research.

- You may not further distribute the material or use it for any profit-making activity or commercial gain

If the publication is distributed under the terms of Article $25 \mathrm{fa}$ of the Dutch Copyright Act, indicated by the "Taverne" license above, 


\title{
Exploring the Material-Induced Transcriptional Landscape of Osteoblasts on Bone Graft Materials
}

\author{
Nathalie Groen, Niloofar Tahmasebi, Fumitaka Shimizu, Yasuteru Sano, Takashi Kanda, \\ Davide Barbieri, Huipin Yuan, Pamela Habibovic, Clemens A van Blitterswijk, \\ and Jan de Boer*
}

During the past decades, there have been major advances in the field of biomaterials, thereby generating a vast variety of materials for a broad range of tissue engineering and regeneration applications. Although gene expression profiling has been used occasionally in biomaterial research, its usefulness for understanding cell-biomaterial interactions should be further explored for it to fulfill its promise as a tool to assess and improve material properties. Here, the transcriptional landscape induced by $\mathbf{2 3}$ materials is explored with a variety of properties within the scope of bone regeneration. An osteoblast cell line is used to identify the gene expression profiles that can be adopted in response to biophysical and chemical cues. It is shown that TGF- $\beta$ and WNT signaling may be involved in the cellular response to osteoinductive materials along with differential cell adhesion kinetics via attenuated FAK signaling. The previously reported effect of calcium and phosphate on BMP2 and TGF- $\beta$ signaling is confirmed and the biological effect of the addition of nanohydroxyapatite in poly ( $\mathrm{D}, \mathrm{L}-\mathrm{lactic}$ acid) polymer particles is studied. Together with future applications, this approach will help researchers understand cellular responses in relation to material properties, which will promote the development of more effective biomaterials for applications in tissue regeneration.

\section{Introduction}

Material properties dictate biological responses in vitro and in vivo. Understanding these cell-material interactions has

Dr. N. Groen, N. Tahmasebi, Dr. D. Barbieri,

Dr. H. Yuan, Prof. P. Habibovic,

Prof. C. A. van Blitterswijk, Prof. J. de Boer

Department of Tissue Regeneration

MIRA Institute for Biomedical Technology

and Technical Medicine

University of Twente

Enschede, $7500 \mathrm{AE}$, The Netherlands

E-mail: jan.deboer@maastrichtuniversity.nl

Dr. F. Shimizu, Dr. Y. Sano, Prof. T. Kanda

Department of Neurology and Clinical Neuroscience

Yamaguchi University Graduate School of Medicine

Yamaguchi 755-8505, Japan

D. Barbieri, H. Yuan

Xpand Biotechnology BV

Prof. Bronkhorstlaan 10-D, 3723 MB, Bilthoven, The Netherlands

Prof. P. Habibovic, Prof. C. A. van Blitterswijk, Prof. J. de Boer

MERLN Institute for Technology-Inspired Regenerative Medicine

Maastricht University

6200 MD, Maastricht, The Netherlands

DOI: 10.1002/adhm.201500171 been subject to extensive research in the last decade. A body of work has emerged on the modulation of cell morphology and behavior by material properties such as surface roughness, topography, chemistry, and elasticity. ${ }^{[1-3]}$ Increasingly, instead of assessing cellular responses to individual material properties or material candidates, investigations have adopted a highthroughput approach with the emergence of libraries of varying chemistries, topographies, and stiffness for instance. ${ }^{[4-8]}$ Combinatorial libraries were also designed to investigate the multifactorial effect of material properties. ${ }^{[9-11]}$ With these developments, the biomaterials field has begun to undertake a high-throughput materiomics approach to address the biological effects of material properties. ${ }^{[12]}$

The characterization of cellular responses to various materials and properties has been mainly focused on cell adhesion, proliferation, self-renewal, migration, and differentiation. Indeed, only a limited number of studies have attempted to unravel the biological mechanisms preceding the observed functional readouts. While mostly low-throughput techniques such as quantitative RT-PCR and western blotting have been used, gene expression microarrays allow the investigation of the biology underlying the cellular responses to material properties in a high-throughput fashion. Historically, this technique has shown its usefulness for investigating biological signaling pathways, studying mechanisms involved in development, disease and cell niches, and in investigating the effect of therapeutics in pharmacology. ${ }^{[13-19]}$ Gene expression microarray technology allows a global measurement of nearly all known protein-coding genes. Within the context of biomaterials research, the cellular responses to different surface structures have been investigated using gene expression profiling. ${ }^{[5,20-22]}$ Also, gene expression and networks were analyzed on ceramic/collagen composites, electrospun and spin-coated materials, and different ceramics in order to understand the cellular response to the presented physicochemical stimuli. ${ }^{[23-25]}$

We previously observed an effect of different ceramic materials at the gene expression level and have shown that gene expression profiling can provide insights into molecular mechanisms involved in the phenotypical effects. ${ }^{[25-28]}$ In this study, 
Table 1. Overview of the 23 materials included in this study that were subjected to transcriptional profiling in osteoblasts.

\begin{tabular}{|c|c|c|}
\hline Name & Materials & Type \\
\hline $\mathrm{HAa}$ & $\mathrm{HA}-\mathrm{Ts}=1150^{\circ} \mathrm{C}$ & Ceramic \\
\hline HAb & $\mathrm{HA}-\mathrm{Ts}=1250^{\circ} \mathrm{C}$ & \\
\hline $\mathrm{HAc}$ & $\mathrm{HA}-\mathrm{Ts}=1100^{\circ} \mathrm{C}$ & \\
\hline $\mathrm{BCPa}$ & $\mathrm{HA} / \mathrm{TCP}(80 / 20)-\mathrm{Ts}=1150^{\circ} \mathrm{C}$ & \\
\hline $\mathrm{BCPb}$ & $\mathrm{HA} / \mathrm{TCP}(80 / 20)-\mathrm{Ts}=1300^{\circ} \mathrm{C}$ & \\
\hline $\mathrm{BCPc}$ & $\mathrm{HA} / \mathrm{TCP}(80 / 20)-\mathrm{Ts}=1150^{\circ} \mathrm{C}$ & \\
\hline BCPd & $\mathrm{HA} / \mathrm{TCP}(70 / 30)-\mathrm{Ts}=1150^{\circ} \mathrm{C}$ & \\
\hline $\mathrm{BCPe}$ & $\mathrm{HA} / \mathrm{TCP}(60 / 40)-\mathrm{Ts}=1150^{\circ} \mathrm{C}$ & \\
\hline $\mathrm{TCPa}$ & $\beta \mathrm{TCP}-\mathrm{Ts}=1050^{\circ} \mathrm{C}$ & \\
\hline $\mathrm{TCPb}$ & $\beta \mathrm{TCP}-\mathrm{Ts}=1100^{\circ} \mathrm{C}$ & \\
\hline PLA & PLA & Polymer \\
\hline PLA-OCP & PLA-OCP coated & $\mathrm{CaP}$ coating \\
\hline PLAC & $\mathrm{PLA} / \mathrm{nCaP}(50$ wt\%) & Composite \\
\hline $\mathrm{PCa}$ & $\mathrm{PLA} / \mathrm{nCaP}(50 \mathrm{wt} \%), 0 \mathrm{~m} \mathrm{NaOH}$ & \\
\hline $\mathrm{PCb}$ & PLA/nCaP (50 wt\%), 0.125 м NaOH & \\
\hline PCc & $\mathrm{PLA} / \mathrm{nCaP}(50 \mathrm{wt} \%), 0.25 \mathrm{~m} \mathrm{NaOH}$ & \\
\hline $\mathrm{PCd}$ & $\mathrm{PLA} / \mathrm{nCaP}(50 \mathrm{wt} \%), 0.5 \mathrm{M} \mathrm{NaOH}$ & \\
\hline $\mathrm{PCe}$ & $\mathrm{PLA} / \mathrm{nCaP}(50 \mathrm{wt} \%), 1 \mathrm{~m} \mathrm{NaOH}$ & \\
\hline bECM & Decellularized trabecular bone & \\
\hline DBM & Demineralized and decellularized trabecular bone & \\
\hline $\mathrm{Ti}$ & Porous titanium & Titanium \\
\hline Ti-OCP & Porous titanium-OCP coated & $\mathrm{CaP}$ coating \\
\hline PS & Polystyrene & Polymer \\
\hline
\end{tabular}

The type of material is listed in the third column. Detailed fabrication processes and descriptions of these materials are provided in the Supporting Information.

we report the cellular response to a set of 23 varying materials using a genomics approach. These materials include a wide variety commonly used in the context of bone repair and regeneration such as ceramics, demineralized bone matrix (DBM), composites, and metals. The biological effect of the majority of these materials has been previously investigated in vitro (e.g. cell proliferation and osteogenic differentiation) or in vivo (e.g. bone-forming capacity). Based on transcriptional profiles, we correlated material properties to biological responses (i.e. in vivo osteoinductive capacity and known molecular mechanisms) in order to understand the molecular effects of cell-biomaterial interactions. This study shows a genomic approach to study material properties in relation to their biological effect.

\section{Results and Discussion}

In order to map the material-induced molecular responses elicited in cells, the transcriptional profiles of an osteosarcoma-derived osteoblast cell line (MG-63) cultured on a set of 23 different materials were studied and compared. The materials, summarized in Table 1, are commonly used or studied as potential bone substitute materials. In order to understand the molecular mechanisms induced upon interaction with the biomaterial, early gene expression variations were assessed. As such, the gene expression profiles induced in the osteoblasts by different calcium phosphate ceramics, polymers, and composites thereof, titanium, ceramic coated surfaces, demineralized (DBM), and decellularized bone matrices (bECM) were compared after $48 \mathrm{~h}$ of culture. We have previously shown that this osteoblast cell line, commonly used in biomaterials research, is highly responsive at the gene expression level to ceramics with varying surfaces. ${ }^{[29]}$ In the work reported here, the biological effects of the materials are studied with the aim of demonstrating the use of transcriptional profiling in investigating cell-material interactions and cellular responses to materials in relation to their properties.

\subsection{General Transcriptional Differences Induced by Materials}

\subsubsection{General Observations}

DNA microarrays assess the expression of over 47000 probes (Illumina), simultaneously representing nearly all the proteincoding genes (over 20 000) from the human genome. In order to explore the general expression variations induced by the different materials (i.e. the similarities and differences between the gene expression profiles), principal component analysis (PCA), and t-distributed stochastic neighbor embedding (t-SNE) were applied. ${ }^{[30]}$ These tools give an indication on the general (PCA) and the local structure, through minimizing the influence of large differences (t-SNE), of the data. Both PCA (Figure 1A) and t-SNE plot (Figure 1B) show a clustering of the biological replicates of each material, confirming the accuracy and reproducibility of gene expression profiling in this context.

The first principal component (PC1, X-axis in Figure 1A) encompasses the largest variations in the dataset $(66.4 \%$ of the total variation) and reveals a cluster of two polymer/ceramic composite materials on the right of PC1 (cluster 1), whereas the majority of the materials (i.e. all ceramics, polymers, titanium, DBM, and bECM) cluster together, having a more similar expression profile (in cluster 3), with respect to PC1 than to the profiles represented by cluster 1 . The second principal component accounts for $6.7 \%$ of the total observed variation and is uncorrelated to the variation represented by PC1. This PC2 reveals the variations within the different classes of materials. MG-63 cultured on polystyrene and OCP coated titanium cluster separately (in cluster 4). Furthermore, the local structure of the data, reflected by the t-SNE plot (Figure 1B), confirms that the ceramics generally cluster with each other and with a group containing the PLA, the PLA composite, and bECM (cluster 3). In addition to the information obtained by PCA, t-SNE reveals that titanium, DBM, polystyrene, OCP coated titanium, and TCPa do not cluster with the other materials and BCPa. Moreover, the different composites cluster separately in two distinct clusters (PCa,b in cluster 1 and PCc,d,e in cluster 2 in Figure 1B).

The aforementioned results indicate that the differential transcriptional profiles induced by the materials in cluster 1 in the PCA (polymeric composites $\mathrm{PCa}$ and $\mathrm{PCb}$ ) and cluster 4 (OCP-coated titanium and tissue culture polystyrene) mask the smaller differences between the different material types. 
A

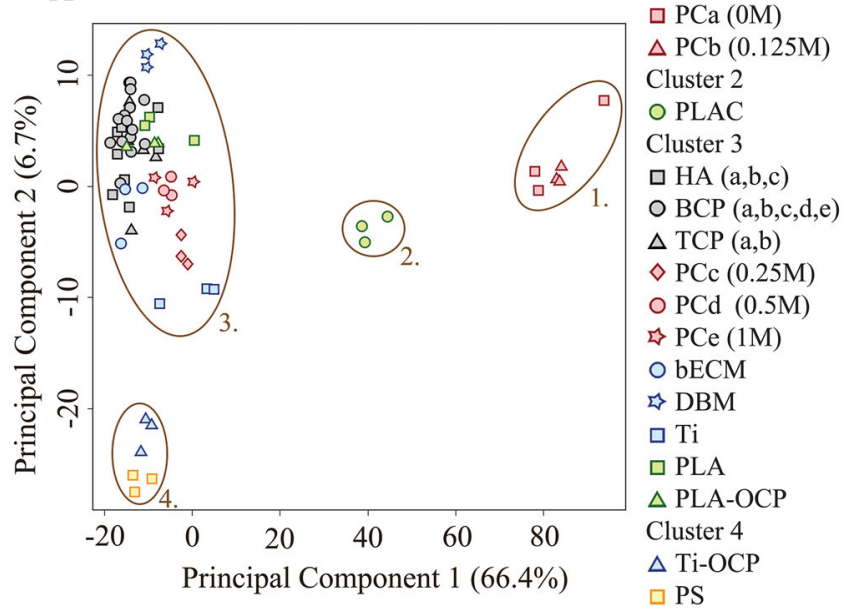

B

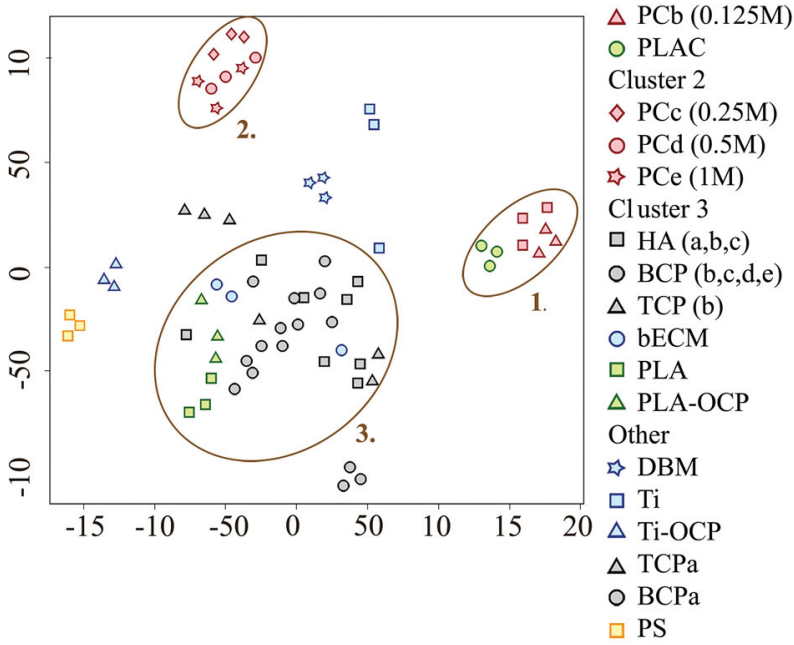

Figure 1. Relationship between the genetic profiles of osteoblasts induced by the different materials. a) PCA plot representing the general transcriptional differences between the materials and B) t-SNE plot focused on the local differences between the samples without emphasis on the large variations.

In general, we observed that the gene expression differences are dominated by the material chemistry. However, it is not only chemistry that plays a role, since a general cluster is observed both in PCA and t-SNE that contains ceramics, polymers and bone ECM (bECM). Indeed, it is reported that the biophysical properties of materials, such as surface structure and mechanical properties, largely influence cellular behavior. ${ }^{[31-34]}$

\subsubsection{Effects Induced by Surface Treatment}

PCA shows that the largest variation, represented along PC1, is significantly influenced by the difference between the composite materials treated with varying concentrations of $\mathrm{NaOH}$ (Figure 1A). The composite materials treated without $\mathrm{NaOH}(0 \mathrm{M} \mathrm{NaOH}$; $\mathrm{PCa})$ cluster with the ones treated with the lowest concentration $(0.125 \mathrm{M}$; $\mathrm{PCb})$ in cluster 1 , in contrast to the composites treated with three higher concentrations $(0.25,0.5$, and $1 \mathrm{M}$; PCc-e), which group with the rest of the materials (cluster 3 in Figure 1A). This clustering suggests that the composite of PLA and nanohydroxyapatite without any surface treatment or with only a mild surface treatment induces a specific but broad effect that is absent when the surface is etched with higher concentrations of $\mathrm{NaOH}$. Differential expression between these two clusters of composites revealed 17173 probes (representing 11148 detected genes) with a $p$-value below 0.05 . As a reference, only 2145 probes are significantly differentially expressed between cells cultured on bECM and DBM, illustrating the massive changes occurring between these composite materials. SEM images (Figure 2) indicate a difference in surface roughness paralleling the alkali $\mathrm{NaOH}$ treatment; however, no apparent distinction based on these surfaces can be made between the materials assembled in both clusters. Generic and qualitative chemical characterization of the surfaces shows the presence of both calcium and phosphate in all five materials, but no major differences in elemental composition (Figure S1, Supporting Information).

However, conclusive observations on the differences between the surfaces require more precise and quantitative chemical and surface characterization methods. Previously, it was reported that this specific alkali treatment of similar composite materials did not alter the chemistry of the surface. ${ }^{[35]}$ It removes the polymer from the surface by hydrolysis and hence exposes uniformly nanostructured apatite particles. Increasing $\mathrm{NaOH}$ concentration increases the surface roughness, surface hydrophilicity, and thickness of the apatite layer. It was shown that the increasing surface roughness of PLA composites by means of $\mathrm{NaOH}$ treatment resulted in decreased proliferation and increased ALP activity in hMSCs. ${ }^{[35]}$ Moreover, the gene expression profiles of MG-63 cultured on the uncoated or OCPcoated PLA with a lower molecular weight clustered with the ceramics and the PLA composites etched with higher concentrations of $\mathrm{NaOH}$ (Figure 1A). The composite from this low molecular weight PLA, PLAC, is fabricated similarly to the

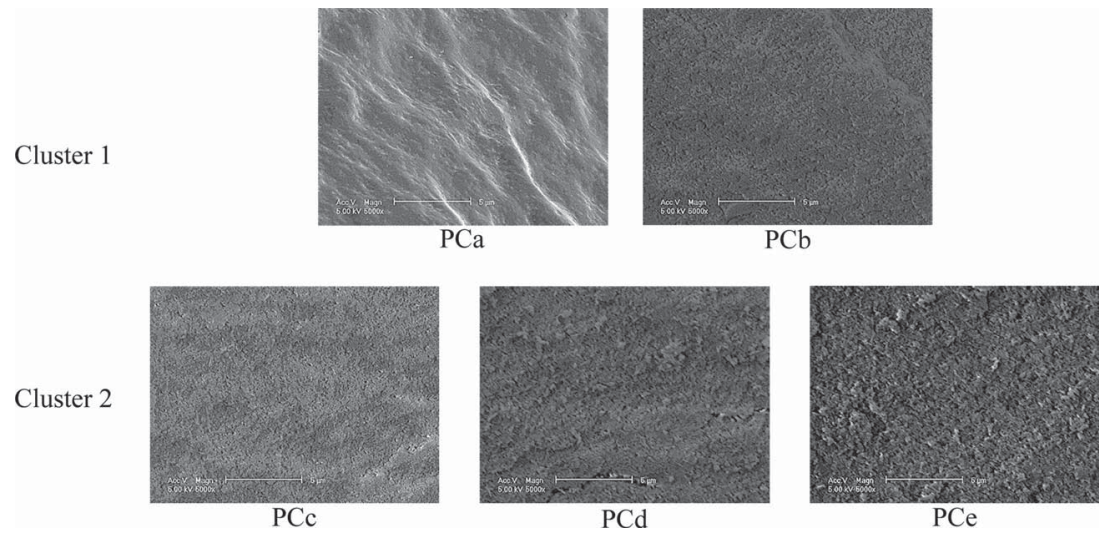

Figure 2. SEM images showing the surface structure of the five polymeric-calcium phosphate composites treated with increasing concentrations of $\mathrm{NaOH}, \mathrm{PCa}$-e treated with $0,0.125,0.25$, 0.5 , and $1 \mathrm{M}$, respectively. 
A

Analysis top 500 probes contributing to PC1

\begin{tabular}{|c|c|c|c|c|}
\hline Signalling pathways & & & $P$ value & Ratio \\
\hline EIF2 Signaling & & & $5.0 \mathrm{E}-75$ & 0.359 \\
\hline Regulation of elF4 and p70S & 6K Signalin & & $1.3 \mathrm{E}-31$ & 0.222 \\
\hline mTOR Signaling & & & $5.0 \mathrm{E}-24$ & 0.169 \\
\hline Mitochondrial Dysfunction & & & 0.0005 & 0.067 \\
\hline NRF2-mediated Oxidative S & ress Respo & & 0.0074 & 0.054 \\
\hline Remodeling of Epithelial Ad & erens Jun & tions & 0.0095 & 0.091 \\
\hline RhoGDI Signaling & & & 0.020 & 0.047 \\
\hline Protein Ubiquitination Path & vay & & 0.024 & 0.042 \\
\hline ILK Signaling & & & 0.024 & 0.049 \\
\hline RhoA Signaling & & & 0.025 & 0.061 \\
\hline Signaling by Rho Family GTP & ases & & 0.029 & 0.040 \\
\hline Hypoxia Signaling in the Car & diovascula & System & 0.033 & 0.078 \\
\hline Actin Cytoskeleton Signaling & & & 0.049 & 0.039 \\
\hline Caveolar-mediated Endocyt & sis Signali & & 0.049 & 0.062 \\
\hline $\mathrm{B}$ & & & & \\
\hline Analysis top 500 probes $\mathrm{c}$ & ontributin & to PC1 & & \\
\hline Metabolic pathways & $P$ value & Ratio & & \\
\hline Oxidative Phosphorylation & 4.6E-05 & 0.095 & & \\
\hline Glycolysis I & 7.4E-03 & 0.182 & & \\
\hline Gluconeogenesis I & 7.4E-03 & 0.182 & & \\
\hline
\end{tabular}

Figure 3. Pathway analysis of the general differences between the materials. A) Significantly overrepresented signaling and B) metabolic pathways in the top 500 probes contributing to the first principal component of the PCA reflecting the largest variations between the different materials. The $p$-value indicates the probability of association of the molecules with the pathways and the ratio is calculated between the number of genes of interest associated with the pathway and the total number of genes that make up the pathway. C) The Venn diagram represents the overlap between the different genes represented in the three highly overrepresented signaling pathways.

composites PCa-e and induces an expression profile that more closely resembles the composites with low $\mathrm{NaOH}$ treatment (cluster 1) than the uncoated PLA (in cluster 3). This observation is confirmed in the t-SNE plot where PLAC occupies cluster 1 together with the non- or mildly surface treated composites (Figure 1B).

To gain insights into the mechanisms behind the large differences induced by the composites in cluster 1 , the top 500 probes contributing to the abovementioned PC1 were ranked based on their contribution weight and the differentially expressed genes with substantial effect size (absolute fold change >4) were subjected to pathway analysis using ingenuity pathway analysis (IPA) and Kyoto Encyclopedia of Genes and Genomes (KEGG) annotation database. The highly overrepresented signaling pathways in PC1 are "eIF2 signaling," "regulation of eIF4 and P70S6K signaling", and "mTOR signaling" (Figure 3A). Noteworthy, the genes in these three overrepresented pathways largely overlap, as can be observed in the Venn diagram represented in Figure 3C. Also, the molecules contributing to the overrepresentation of "mTOR" and "eIF4 and p70S6K signaling" are nearly all involved in "eIF2 signaling". ${ }^{[36]}$ The dominance of this pathway is mainly due to the negative contribution of
60 ribosomal protein-coding and four eIF genes in the first principal component. Eukaryotic initiation factor (eIF) is a family of proteins required for the initiation phase of protein translation. ${ }^{[37]}$ Mammalian target of rapamycin (mTOR) signaling regulates cell growth, proliferation motility, and protein synthesis and translation, reflecting the availability of growth factors, nutrients, ATP levels, and amino acids. Downstream effects include translation of mRNA, ribosome biogenesis, and activation of transcription leading to mitochondrial metabolism. ${ }^{[36,38,39]}$

This is further supported when the overrepresented metabolic pathways are considered: "oxidative phosphorylation," "glycolysis I," and "gluconeogenesis" are overrepresented metabolic pathways in PC1 (Figure 3B), suggesting lower metabolic activity and energy production. Then, to address the directionality of the observed differences, we analyzed the specific differences between the composites in clusters 1 and 2, reflecting the cellular responses modulated by $\mathrm{NaOH}$ treatment. Analyzing the pathways affected in the differentially regulated genes resulted in four significant signaling pathways, with minimum number of overlapping molecules. These pathways point again toward a lower transcriptional and metabolic state of the cells on the materials in cluster 1 , similar to the PC1 analysis. Here, "RAN signaling" refers to protein and RNA transport into and from the nucleus, "mitotic roles in polo-like kinase" indicate a difference in cell cycle regulators and the "PI3K/AKT pathway" is important in signal transduction of cytokines, growth factors or extracellular proteins (Figure S2A, Supporting Information). Similarly, ribosome pathway, DNA replication, cell cycle, and amino acid synthesis were enriched by these genes as evaluated by KEGG pathway analysis. ${ }^{[40]}$ (Figure S2B, Supporting Information).

Besides protein synthesis and metabolic pathways, other physiological processes were affected as a result of chemical etching. Specifically, the down regulation in cluster 1 of the main molecules involved in the overrepresented "remodeling of epithelial adherens junctions", "actin cytoskeleton remodeling," and "integrin signaling" (illustrated in Figure S3 in the Supporting Information) in both abovementioned analyses hint toward differential cell adhesion and cytoskeleton signaling. Notably, $\beta 1$ integrin (ITGB1) is massively down regulated with a 14.9-fold change (average of three different microarray probes targeting ITGB1) in the two composites with no or low treatment in comparison to the three other composites. Also integrin alpha $\mathrm{V}$ is 7.15 -fold down regulated. Besides, commonly assessed marker genes for osteogenic function (RUNX2, ALPL, BMP2, and COL1A1) did not reveal differences larger than 1.8fold between the two clusters. Osteocalcin was threefold upand osteonectin was sixfold down regulated on the composites treated with higher concentrations of $\mathrm{NaOH}$.

Using principal component analysis, we are able to compare the cellular responses to various materials. Based on the aforementioned transcriptional analyses, we noticed that the addition of nanoHA to PLA influences the surrounding cellular environment, thereby negatively affecting cell metabolism and downstream translation, which is prevented by the alkali treatment and removal of the polymer from the surface. Further analysis of these materials and their properties would unveil their influence on the large expression differences observed using genomic analyses. 


\subsection{Correlating Gene Expression to In Vivo Readouts}

In vitro cellular behavior in response to a biomaterial may give useful insights into their observed in vivo responses. Correlating gene expression profiles to a known in vivo observation (e.g. coagulation or fibrous capsule formation upon prosthesis implantation, or peri-implant pseudotumor formation) may lead to new pathways to improve the biomaterial. Osteoinductivity, i.e., the in vivo bone-inducing capacity upon implantation at heterotopic sites, is a very interesting material property for bone regeneration purposes. This phenomenon has been studied for decades in our group and by others, while a thorough understanding of the underlying molecular mechanisms is still missing. In order to unravel these mechanisms, we correlated in vitro gene expression patterns on various materials to their in vivo osteoinductive potential. We studied five ceramic materials with known osteoinductivity based on previously published data and observations from our group. Specifically, $\mathrm{HAa}, \mathrm{BCPa}$, and TCPa are able to induce bone formation when implanted intramuscularly in a large animal model, whereas $\mathrm{HAb}$ and $\mathrm{BCPb}$ are not. ${ }^{[3,41-45]}$ SEM images of the surface of these ceramics are depicted in Figure S4 (Supporting Information). Interestingly, the remaining materials, not yet tested in vivo, can be compared in terms of genes differentially regulated in the materials with known osteoinductivity. It is important to note that the composite materials were removed as the large general differences might bias further analysis.

We first compared the osteoinductive (OI) ceramics (HAa, $\mathrm{BCPa}$, and $\mathrm{TCPa}$ ) with the nonosteoinductive (nOI) ones ( $\mathrm{HAb}$ and $\mathrm{BCPb}$ ) resulting in a gene list of 2576 probes significantly $(p<0.05)$ differentially expressed. Then, we used this list to plot all materials using PCA to compare them relative to the OI and nOI ceramics. The resulting plot revealed that the OI materials are spread in the upper region and the nOI cluster on the lower right part of the graph (Figure 4A). Most of the remaining materials cluster together with the nOI materials, including PLA, PLA coated with OCP and DBM. When considering PC1, OI materials cluster in the middle, nOI are on the right, and OCP-coated titanium is observed together with MG-63 cultured on polystyrene on the left.

Next, we identified the genes that correlate quantitatively to the osteoinductivity, because the above-discussed gene list appears to be highly influenced by the differential profile induced by BCPa (Figure 4A) as its induced profile clusters separately from the remaining OI materials which cluster toward the other materials. The quantity of osteoinduction refers to the amount of bone that is induced by the materials when implanted intramuscularly in diverse animal models. Indeed, the three OI materials have gradually increasing bone formation, from HAa to BCPa to TCPa. ${ }^{[3,41,45,46]}$ As such, genes were considered when their expression paralleled the extent of material-induced bone formation (i.e. increasing or decreasing expression from $[\mathrm{HAb}, \mathrm{BCPb}]<[\mathrm{HAa}]<[\mathrm{BCPa}]<[\mathrm{TCPa}])$ by applying a linear filtering constraint to the profile analysis. The resulting gene list contained 2269 probes (correlation $p<0.05$ ). The subsequent PCA (Figure 4B) for this list confirmed a difference between the ceramics, with the most osteoinductive ones (TCPa and $\mathrm{BCPa}$ ) in the top and the nonosteoinductive ceramics on the right $(\mathrm{BCPb}$ and $\mathrm{HAb})$. Furthermore, the remaining
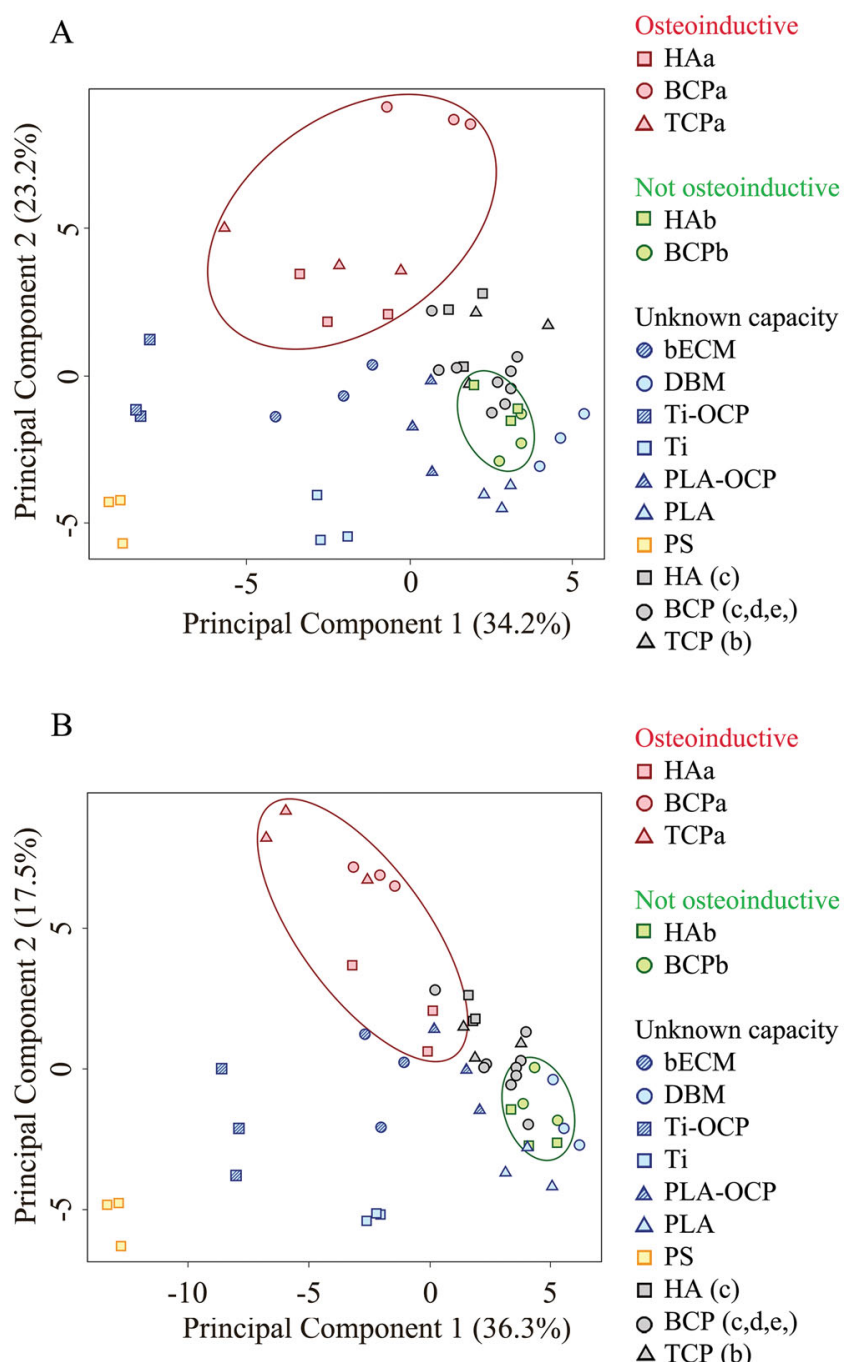

Osteoinductive
$\square \mathrm{HAa}$
$\circ \mathrm{BCPa}$
$\triangle \mathrm{TCPa}$
Not osteoinductive
$\square \mathrm{HAb}$
O BCPb
Unknown capacity
o bECM
O DBM
⿴囗大 Ti-OCP
$\square \mathrm{Ti}$
$\triangle \mathrm{PLA}-\mathrm{OCP}$
$\triangle \mathrm{PLA}$
$\square \mathrm{PS}$
$\square \mathrm{HA}(\mathrm{c})$
O BCP (c,d,e,
$\triangle \mathrm{TCP}(\mathrm{b})$

Figure 4. Analysis of the genes correlating to the osteoinductive property of ceramics. A) PCA plot based on genes differentially expressed (fold change $>1.4, p<0.05$ ) between the two non-osteoinductive ( $\mathrm{HAb}$ and $\mathrm{BCPb}$ ) and three osteoinductive materials ( $\mathrm{HAa}, \mathrm{BCPa}$, and $\mathrm{TCPa})$. B) PCA plot based on genes, with expression paralleling the extent of osteoinduction of the five materials with known osteoinductive capacity.

ceramics are distributed between the OI HAa and the nOI BCPb and $\mathrm{HAb}$. The expression profile of MG-63 cultured on OCP coated titanium is shifted to the left and upward, toward the expression of OI ceramics, in comparison to titanium. Indeed, titanium coated with OCP has been reported to be osteoinductive when implanted intramuscularly, but it induces less bone in comparison to osteoinductive BCP after 6 weeks of implantation. ${ }^{[47,48]}$ Moreover, as expected based on the effect of OCP coating, the expression profile induced by PLA shifted slightly toward the OI side in the PCA plot when an OCP coating is applied (Figure 4B). DBM, PLA, and titanium are clustered near the nOI ceramics. In conclusion, using correlations to in vivo observations, PCA on diverse gene lists may describe the in vivo osteoinductive capacity of other materials.

The transcriptional profiles can give insights into the molecular mechanisms of in vivo biomaterial behavior. In order to 
A

\begin{tabular}{lcc}
\hline \multicolumn{3}{c}{ Analysis of the 114 differentially expressed } \\
Signalling pathways & P value & Ratio \\
\hline FAK Signaling & 0.002 & 0.061 \\
Sertoli Cell-Sertoli Cell Junction Signaling & 0.007 & 0.038 \\
Integrin Signaling & 0.009 & 0.034 \\
Paxillin Signaling & 0.014 & 0.046 \\
Remodeling of Epithelial Adherens Junctions & 0.020 & 0.061 \\
Agrin Interactions at Neuromuscular & 0.020 & 0.060 \\
$\quad$ Junction & 0.036 & 0.026 \\
Actin Cytoskeleton Signaling & 0.036 & 0.035 \\
Epithelial Adherens Junction Signaling & 0.036 & 0.042 \\
VEGF Signaling & 0.036 & 0.032 \\
Tight Junction Signaling & 0.036 & 0.032 \\
Germ Cell-Sertoli Cell Junction Signaling & & \\
\hline
\end{tabular}

B

\begin{tabular}{lcc}
\hline \multicolumn{2}{l}{ Analysis of the 1703 gradually correlating molecules } & \\
Signalling pathways & P value & Ratio \\
\hline Molecular Mechanisms of Cancer & 0.001 & 0.152 \\
Wnt/B-catenin Signaling & 0.001 & 0.194 \\
Factors Promoting Cardiogenesis in Vertebrates & 0.004 & 0.220 \\
Mitotic Roles of Polo-Like Kinase & 0.004 & 0.250 \\
Regulation of the Epithelial-Mesenchymal Transition & 0.019 & 0.160 \\
Pathway & 0.031 & 0.198 \\
Regulation of Actin-based Motility by Rho & 0.031 & 0.190 \\
p53 Signaling & 0.039 & 0.229 \\
Cell Cycle: G2/M DNA Damage Checkpoint & & \\
Regulation &
\end{tabular}

\begin{tabular}{l} 
C \\
\begin{tabular}{llll} 
Analysis of the 235 overlapping molecules \\
Signalling pathway & P value & Ratio \\
\hline Oncostatin $\mathrm{M}$ signalling & 0.016 & 0.147
\end{tabular} \\
\hline
\end{tabular}

Figure 5. Pathway analysis of the genes correlating to the osteoinductive property of ceramics. A) The significantly overrepresented pathways in the 114 genes solely differentially expressed between $\mathrm{OI}$ and $\mathrm{nOI}$ materials. B) The pathways significantly overrepresented in 1703 genes with expression correlating with the gradually increasing bone formation between the OI materials. C) The significantly overrepresented pathway in the 235 overlapping molecules between both gene lists. The $p$-value indicates the probability of association of the molecules with the pathways and the ratio is calculated between the number of genes of interest associated with the pathway and the total number of genes that make up the pathway. D) The Venn diagram represents the overlap between the two abovementioned gene lists related to osteoinductivity.

impinge on the molecular responses in relation to osteoinductivity and quantity of bone formation, we further analyzed these two gene lists. To understand the differences between the two lists, we deconvolved them separating the overlapping molecules and analyzed the subsets individually (Figure 5). First, IPA analysis on the 114 molecules that are differentially expressed between OI and nOI, without the overlapping molecules from the quantitative OI list, pointed toward a role for cell adhesion and actin cytoskeleton remodeling (Figure 5A,D).
Indeed, all the listed pathways are based on focal adhesion molecules (ITGB1, VCL), cytoskeletal molecules (ACTB, ACTG1, TUBB), and PTEN. Notably, the overrepresentation of "VEGF signaling" pathway is also mainly based on a few of these cytoskeletal molecules. Second, the 1703 genes correlating to the osteoinductive quantity (excluding the overlapping differentially expressed genes) revealed overrepresentation of signaling pathways such as "Wnt/B-catenin," "regulation of epithelial-mesenchymal transition," and "molecular mechanisms of cancer" (Figure 5B,D). "Molecular mechanisms in cancer" describes the signaling pathways involved in intra- and intercellular communication leading to malignant tumor phenotypes. This broad pathway covers "GPCR signaling," "ras/integrin signaling," "AKT signaling," “TGF- $\beta /$ BMP signaling," "WNT signaling," "Notch and Hedgehog (Hh) signaling," and "death receptor signaling." The molecules contributing to this overrepresentation are included in subsets of the other signaling pathways, mainly "BMP and TGF signaling" (e.g. BMP2, -4, and -6, BMPR2, TGFR2), "WNT/ $\beta$ catenin signaling" (e.g. several Frizzled and related genes, DKK1), "interferon signaling," and several MAP kinases and Rho family members. Third, the 235 overlapping molecules between the two gene lists converge into "oncostatin M signaling." Activated monocytes and lymphocytes produce oncostatin M (OSM), a member of the interleukin 6 (IL-6) hematopoietic cytokine family, acting locally on stromal cells, which in turn enhance their production of IL-6 and LIF to stimulate the inflammatory response. OSM has not only been shown to stimulate osteoblast mineralization and differentiation but also osteoblastic differentiation of MSCs. ${ }^{[49]}$ Moreover, OSM has been shown to enhance osteoinduction, when exogenously added to a critical sized defect. ${ }^{[0]}$

The above analyses suggest that OI materials require oncostatin $\mathrm{M}$ signaling and differential cell adhesion, plausibly enabled by their differential microstructured surfaces (SEM images in Figure S4 in the Supporting Information), and that the quantity of bone is determined by signaling pathways such as TGF and WNT. ${ }^{[31,33,43,44,51]}$ To support this, we observed that the molecules involved in FAK signaling (Figure S5, Supporting Information) are mainly down regulated in OI materials. Focal adhesions (FA) link extracellular signals, integrating growth factor and integrin signaling from the ECM via the actin cytoskeleton to the nucleus. ${ }^{[52]}$ FA kinase (FAK) signaling controls cell adhesion and migration and together with downstream ERK/MAPK has been shown to be modulated by nano- and microtopographies, where more mature FA were observed on flat surfaces. ${ }^{[53]}$ FAK signaling and high FAK turnover has been associated with the disassembly of adhesion sites and subsequently increased migration, whereas reduced FAK signaling has been associated with a less migratory phenotype. ${ }^{[54]}$ Both PTEN and the Rho family members, together with the cytoskeletal genes, regulate actin remodeling and cell shape, which might be a result of FAK signaling. ${ }^{[55]}$ Also, the analyses suggest that TGF- $\beta$ and WNT signaling determine the amount of bone formation induced by ceramics. The link between molecules involved in TGF- $\beta$ signaling, by means of BMP2 and -4 and BMPR2, WNT signaling and osteoblastic responses to rough titanium surfaces have been reported previously. ${ }^{[31,51]}$ Overall, correlating in vitro gene expression profiles with in vivo observed effects gives insights into the molecular 

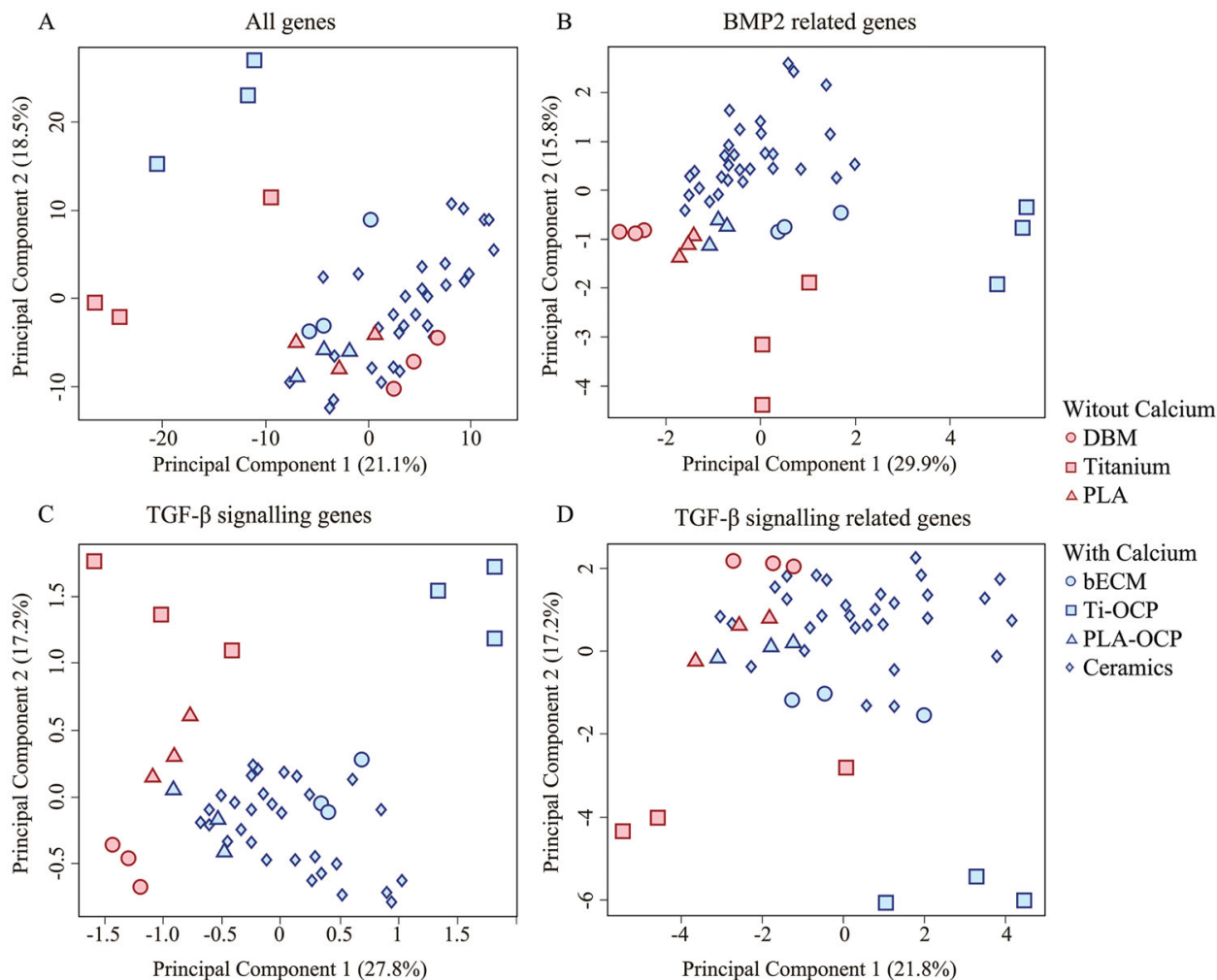

Figure 6. PCA plots based on several gene sets to address the relationship between BMP2 signaling and materials with calcium and phosphate. A) PCA on all genes (19 673 probes) detected in the microarray, B) BMP2 related genes (651 probes), C) TGF- $\beta$ signaling molecules (141 probes), and D) molecules related to the genes involved in the TGF- $\beta$ signaling pathway (1504 probes). The materials without calcium and phosphate are represented in red, and the materials containing these ions are represented in blue.

mechanisms induced by biomaterials. These insights may enable further hypotheses-driven in vitro and in vivo experimental work to validate the hypothesized mechanisms underlying material-induced bone formation.

\subsection{Investigating Gene Expression in Relation to Material Properties}

Correlating material properties to gene expression profiles improves the understanding and further development of materials. Here, chemistry is used as a readout to couple gene expression profiles to the presence of calcium and phosphate in the materials, since most materials studied in this dataset are calcium phosphate based ceramics or polymer-CaP (calcium phosphate) composite materials. These ions (in solution or incorporated in a material) are known to greatly influence cellular responses, specifically for bone regeneration applications. ${ }^{[25,27,41,56-59]}$ Surface characterization revealed that in addition to all ceramics and composites, bECM, OCP-coated titanium and low molecular weight PLA contained calcium and phosphate, whereas DBM, titanium, and uncoated PLA did not (Figure S6, Supporting Information).

Generally, the transcriptional differences could not be attributed to the presence of calcium and phosphate in the materials, since PCA on all genes did not reveal a cluster with calcium and phosphate baring materials (Ca/P; Figure 6A).
Previous work on the biological effect of calcium phosphate ceramics has shown the upregulation of BMP2 in response to calcium. ${ }^{[27,60]}$ As such, we postulated that calcium and phosphate containing materials differentially affect BMP2 signaling. To investigate this in the context of the biomaterials included in this study, three gene lists were produced. First, 425 genes were listed (represented by 651 microarray probes) on evidence-based interactions with BMP2, by annotation, proven interaction, and pathway or functionally related, using the "endeavor" bioinformatics tool. ${ }^{[61]}$ Second, to obtain a list of probes that are selectively related to functional BMP2 signaling, the full microarray probe set was filtered to obtain 141 probes (representing 90 molecules) actively involved in TGF- $\beta$ /BMP signaling based on information from the KEGG database (KEGG:04350). Last, this list of TGF- $\beta /$ BMP signaling molecules was extended with related genes (using the endeavor bioinformatics tool). Principal component analyses and plots revealed separate clusters of $\mathrm{Ca} / \mathrm{P}$ and non- $\mathrm{Ca} / \mathrm{P}$ baring materials based on BMP2 related (Figure 6B) and TGF- $\beta / B M P$ signaling molecules (Figure 6C). However, this clustering was abolished when TGF- $\beta /$ BMP signaling-related molecules were included (Figure 6D). These findings indicate that the effect of calcium and phosphate incorporated in materials is specifically related to TGF- $\beta /$ BMP signaling. Hence, the link between BMP2 and $\mathrm{Ca} / \mathrm{P}$ via its specific signaling pathway described in the literature is validated by this dataset and the analyses. 

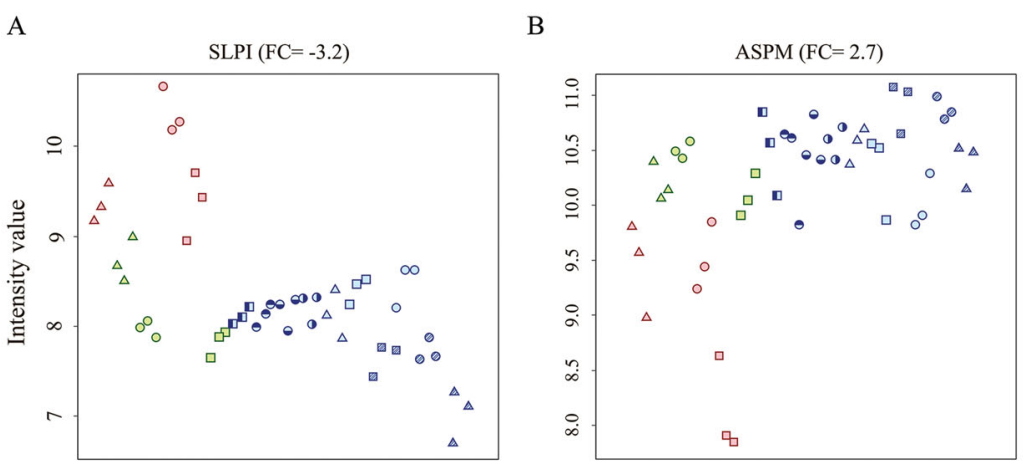

\begin{tabular}{|c|}
\hline $\begin{array}{l}\text { Without Calcium } \\
\triangle \mathrm{PLA} \\
\square \mathrm{Ti} \\
\text { O DBM }\end{array}$ \\
\hline $\begin{array}{l}\text { With Calcium } \\
\triangle \text { PLA-OCP } \\
\square \text { Ti-OCP } \\
\text { o bECM }\end{array}$ \\
\hline 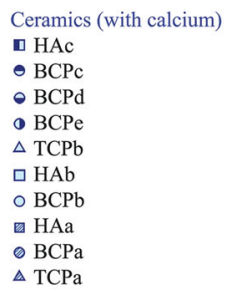 \\
\hline
\end{tabular}

Figure 7. Expression profiles of two differentially expressed genes from the top five between the calcium phosphate containing and deficient materials. A) SLPI negatively and B) ASPM positively correlates to the presence of calcium and phosphate in the materials.

Differential expression analysis between the calcium and phosphate containing materials and the others revealed 4225 significantly different probes. While there are a large number of probes, their effect size is rather small. Only 22 genes showed differences higher than twofold (Table S1, Supporting Information). Since all calcium and phosphate containing materials are combined, it is possible that the comparison, involving various materials with diverse properties, may average out the gene expression differences related to calcium and phosphate presence. To illustrate, the expression pattern of two genes, SLPI and ASPM, from the top five is represented in Figure 7 with an effect size of -3.2 and 2.7-fold respectively. A clear trend between the calcium-containing and calcium-free materials can be observed. Specifically, the regulation of these genes is consistent over the different comparisons: between $\mathrm{Ca} / \mathrm{P}$-coated titanium and uncoated, between bone matrix and demineralized bone matrix and between PLA coated with $\mathrm{Ca} / \mathrm{P}$ and uncoated PLA (Figure 7).

Using the aforementioned analysis, we not only confirmed the previously known relationship between $\mathrm{Ca} / \mathrm{P}$ and $\mathrm{BMP} 2$ in different materials, but also hypothesized that the genes emerging from the differential expression analysis were regulated specifically by calcium or phosphate.

\section{Conclusion and Outlook}

This proof-of-concept study serves to illustrate the usefulness of a genomics approach in biomaterials research. Cell-biomaterial interactions are a subject of intense investigations and we propose transcriptomics as a tool with added value. Using defined analyses, correlations to material properties, and readouts, we discussed the effect of several materials and treatments on the biological response of cells.

General observations on gene expression profiles highlighted a dramatic effect of polymer/ceramic composite materials and alkali surface treatment, not observed in the expression of commonly used osteogenic markers, indicating the added value of genome-wide screening. Moreover, we obtained more insights into the molecular mechanisms induced by osteoinductive materials by correlating transcriptional profiling to osteoinductivity, leading to defined hypotheses for further in vitro validations. Specifically, we hypothesize that besides oncostatin $\mathrm{M}$ signaling, a downregulation of FAK signaling is required in consort with differential TGF- $\beta$ and WNT signaling for materials to be osteoinductive. Additionally, by coupling expression profiles to material properties, we were able to confirm a previous observation reported in the literature, showing that that BMP2 and BMP signaling is influenced by calcium and phosphate.

From this study, new hypotheses evolved from the observed and analyzed differential cell behavior induced by materials, which can be further validated in vitro. Together with future applications, this approach will aid researchers in understanding cellular responses in relation to material properties, which will promote the development of more effective biomaterials for applications in regenerative medicine.

\section{Experimental Section}

Materials: Various materials considered relevant for bone regeneration applications (listed in Table 1) were characterized using scanning electron microscopy (XL30, Environmental SEM-Field Emission Gun, Philips) coupled to energy-dispersive X-ray analyzer (EDAX; Apollo X, Ametek).

Cell Culture: MG-63 (ATCC) were cultured on the different materials and on tissue culture polystyrene.

Transcriptional Profiling: Total RNA was isolated using a Nucleospin RNA isolation kit (Macherey-Nagel), cRNA was synthesized using the Illumina TotalPrep RNA amplification Kit (Ambion). Microarrays were performed using Illumina HT-12 v4 expression Beadchips. Further data processing and statistical tests were performed using $R$ and Bioconductor statistical software and Ingenuity Pathway Analysis (IPA, Qiagen) was used to evaluate the signaling and metabolic pathways overrepresented in the differentially expressed genes. ${ }^{[62]}$ More details on the production and fabrication methods of the materials, cell culture, medium composition, and gene expression analysis are described in the Supporting Information.

\section{Supporting Information}

Supporting Information is available from the Wiley Online Library or from the author. 


\section{Acknowledgements}

This research forms part of the Project P2.04 BONE-IP of the research program of the BioMedical Materials Institute, cofunded by the Dutch Ministry of Economic Affairs.

Received: March 10, 2015

Revised: April 30, 2015

Published online: June 5, 2015

[1] G. C. Reilly, A. J. Engler, J. Biomech. 2010, 43, 55

[2] R. K. Das, O. F. Zouani, Biomaterials 2014, 35, 5278.

[3] S. Samavedi, A. R. Whittington, A. S. Goldstein, Acta Biomater. 2013, 9, 8037.

[4] J. C. Meredith, J.-L. Sormana, B. G. Keselowsky, A. J. García, A. Tona, A. Karim, E. J. Amis, J. Biomed. Mater. Res. Part A 2003, 66A, 483.

[5] M. J. Dalby, N. Gadegaard, R. Tare, A. Andar, M. O. Riehle, P. Herzyk, C. D. Wilkinson, R. O. Oreffo, Nat. Mater. 2007, 6, 997.

[6] J. Lovmand, J. Justesen, M. Foss, R. H. Lauridsen, M. Lovmand, C. Modin, F. Besenbacher, F. S. Pedersen, M. Duch, Biomaterials 2009, 30, 2015.

[7] J. Fu, Y. K. Wang, M. T. Yang, R. A. Desai, X. Yu, Z. Liu, C. S. Chen, Nat. Methods 2010, 7, 733.

[8] K. Chatterjee, L. Sun, L. C. Chow, M. F. Young, C. G. Simon Jr., Biomaterials 2011, 32, 1361.

[9] Y. Mei, K. Saha, S. R. Bogatyrev, J. Yang, A. L. Hook, Z. I. Kalcioglu, S.-W. Cho, M. Mitalipova, N. Pyzocha, F. Rojas, K. J. Van Vliet, M. C. Davies, M. R. Alexander, R. Langer, R. Jaenisch, D. G. Anderson, Nat. Mater. 2010, 9, 768.

[10] Y. Mei, S. Gerecht, M. Taylor, A. J. Urquhart, S. R. Bogatyrev, S.-W. Cho, M. C. Davies, M. R. Alexander, R. S. Langer, D. G. Anderson, Adv. Mater. 2009, 21, 2781.

[11] S. Gobaa, S. Hoehnel, M. Roccio, A. Negro, S. Kobel, M. P. Lutolf, Nat. Methods 2011, 8, 949.

[12] S. W. Cranford, J. de Boer, C. van Blitterswijk, M. J. Buehler, Adv. Mater. 2013, 25, 802.

[13] S. McKinney-Freeman, P. Cahan, H. Li, S. A. Lacadie, H. T. Huang, M. Curran, S. Loewer, O. Naveiras, K. L. Kathrein, M. Konantz, E. M. Langdon, C. Lengerke, L. I. Zon, J. J. Collins, G. Q. Daley, Cell Stem Cell 2012, 11, 701.

[14] J. C. Miller, B. D. Brown, T. Shay, E. L. Gautier, V. Jojic, A. Cohain, G. Pandey, M. Leboeuf, K. G. Elpek, J. Helft, D. Hashimoto, A. Chow, J. Price, M. Greter, M. Bogunovic, A. Bellemare-Pelletier, P. S. Frenette, G. J. Randolph, S. J. Turley, M. Merad, Nat. Immunol. 2012, 13, 888.

[15] T. S. Heng, M. W. Painter, Nat. Immunol. 2008, 9, 1091.

[16] S. M. Chambers, N. C. Boles, K. Y. Lin, M. P. Tierney, T. V. Bowman, S. B. Bradfute, A. J. Chen, A. A. Merchant, O. Sirin, D. C. Weksberg, M. G. Merchant, C. J. Fisk, C. A. Shaw, M. A. Goodell, Cell Stem Cell 2007, 1, 578.

[17] D. R. Rhodes, J. Yu, K. Shanker, N. Deshpande, R. Varambally, D. Ghosh, T. Barrette, A. Pandey, A. M. Chinnaiyan, Neoplasia 2004, $6,1$.

[18] A. Mejias, B. Dimo, N. M. Suarez, C. Garcia, M. C. Suarez-Arrabal, T. Jartti, D. Blankenship, A. Jordan-Villegas, M. I. Ardura, Z. Xu, J. Banchereau, D. Chaussabel, O. Ramilo, PLoS Med. 2013, 10, e1001549.

[19] U. Scherf, D. T. Ross, M. Waltham, L. H. Smith, J. K. Lee, L. Tanabe, K. W. Kohn, W. C. Reinhold, T. G. Myers, D. T. Andrews, D. A. Scudiero, M. B. Eisen, E. A. Sausville, Y. Pommier, D. Botstein, P. O. Brown, J. N. Weinstein, Nat. Genet. 2000, 24, 236.

[20] P. M. Tsimbouri, K. Murawski, G. Hamilton, P. Herzyk, R. O. C. Oreffo, N. Gadegaard, M. J. Dalby, Biomaterials 2013, 34, 2177.
[21] L. E. McNamara, R. Burchmore, M. O. Riehle, P. Herzyk, M. J. P. Biggs, C. D. W. Wilkinson, A. S. G. Curtis, M. J. Dalby, Biomaterials 2012, 33, 2835.

[22] M. J. Dalby, A. Andar, A. Nag, S. Affrossman, R. Tare, S. McFarlane, R. O. Oreffo, J. R. Soc. Interface 2008, 5, 1055.

[23] J. Eyckmans, S. J. Roberts, J. Bolander, J. Schrooten, C. S. Chen, F. P. Luyten, Biomaterials 2013, 34, 4612.

[24] B. A. Baker, P. S. Pine, K. Chatterjee, G. Kumar, N. J. Lin, J. H. McDaniel, M. L. Salit, C. G. Simon Jr., Biomaterials 2014, 35, 6716.

[25] A. M. Barradas, V. Monticone, M. Hulsman, C. Danoux, H. Fernandes, Tahmasebi, Z. Birgani, F. Barrere-de Groot, H. Yuan, M. Reinders, P. Habibovic, C. van Blitterswijk, J. de Boer, Integr. Biol. 2013, 5, 920.

[26] H. Yuan, H. Fernandes, P. Habibovic, J. de Boer, A. M. C. Barradas, A. de Ruiter, W. R. Walsh, C. A. van Blitterswijk, J. D. de Bruijn, Proc. Natl. Acad. Sci. U.S.A. 2010, 107, 13614.

[27] A. M. Barradas, H. A. Fernandes, N. Groen, Y. C. Chai, J. Schrooten, J. van de Peppel, J. P. van Leeuwen, C. A. van Blitterswijk, J. de Boer, Biomaterials 2012, 33, 3205.

[28] J. Doorn, H. A. M. Fernandes, B. Q. Le, J. van de Peppel, J. P. T. M. van Leeuwen, M. R. De Vries, Z. Aref, P. H. A. Quax, O. Myklebost, D. B. F. Saris, C. A. van Blitterswijk, J. de Boer, Biomaterials 2013, 34, 3053.

[29] N. Groen, J. van de Peppel, H. Yuan, J. P. van Leeuwen, C. A. van Blitterswijk, J. de Boer, Biomaterials 2013, 34, 5552.

[30] L. J. P. van der Maaten, in Proc. Twelfth Int. Conf. Artificial Intelligence Statistics 2009, 5, 384.

[31] R. Olivares-Navarrete, S. L. Hyzy, J. H. Park, G. R. Dunn, D. A. Haithcock, C. E. Wasilewski, B. D. Boyan, Z. Schwartz, Biomaterials 2011, 32, 6399.

[32] A. J. Engler, S. Sen, H. L. Sweeney, D. E. Discher, Cell 2006, 126, 677.

[33] P. Habibovic, H. Yuan, C. M. van der Valk, G. Meijer, C. A. van Blitterswijk, K. de Groot, Biomaterials 2005, 26, 3565.

[34] R. Olivares-Navarrete, P. Raz, G. Zhao, J. Chen, M. Wieland, D. L. Cochran, R. A. Chaudhri, A. Ornoy, B. D. Boyan, Z. Schwartz, Proc. Natl. Acad. Sci. U.S.A. 2008, 105, 15767.

[35] D. Barbieri, J. de Bruijn, H. Yuan, in Frontiers in nanobiomedical research: Tissue regeneration: where nano structure meets biology World Scientific, 2014, pp 473-515.

[36] M. Laplante, D. M. Sabatini, J. Cell Sci. 2009, 122, 3589.

[37] E. Schmitt, M. Naveau, Y. Mechulam, FEBS Lett. 2010, 584, 405.

[38] X. Wang, L. E. Campbell, C. M. Miller, C. G. Proud, Biochem. J. 1998, $334,261$.

[39] T. L. Downing, J. Soto, C. Morez, T. Houssin, A. Fritz, F. Yuan, J. Chu, S. Patel, D. V. Schaffer, S. Li, Nat. Mater. 2013, 12, 1154.

[40] H. Ogata, S. Goto, K. Sato, W. Fujibuchi, H. Bono, M. Kanehisa, Nucleic Acids Res. 1999, 27, 29.

[41] H. Yuan, H. Fernandes, P. Habibovic, J. de Boer, A. M. C. Barradas, A. de Ruiter, W. R. Walsh, C. A. van Blitterswijk, J. D. de Bruijn, Proc. Natl. Acad. Sci. 2010, 107, 13614.

[42] H. Yuan, M. van den Doel, S. Li, C. A. van Blitterswijk, K. de Groot, J. D. de Bruijn, J. Mater. Sci. Mater. Med. 2002, 13, 1271.

[43] J. Zhang, X. Luo, D. Barbieri, A. M. C. Barradas, J. D. de Bruijn, C. A. van Blitterswijk, H. Yuan, Acta Biomater. 2014, 3254.

[44] P. Habibovic, M. C. Kruyt, M. V. Juhl, S. Clyens, R. Martinetti, L. Dolcini, N. Theilgaard, C. A. van Blitterswijk, J. Orthop. Res. 2008, 26, 1363.

[45] N. L. Davison, X. Luo, T. Schoenmaker, V. Everts, H. Yuan, F. Barrere-de Groot, J. D. de Bruijn, Eur. Cell Mater. 2014, 27, 281.

[46] H. Yuan, C. A. van Blitterswijk, K. de Groot, J. D. de Bruijn, Tissue Eng. 2006, 12, 1607.

[47] P. Habibovic, C. M. van der Valk, C. A. van Blitterswijk, K. De Groot, G. Meijer, J. Mater. Sci. Mater. Med. 2004, 15, 373. 
[48] P. Habibovic, J. Li, C. M. van der Valk, G. Meijer, P. Layrolle, C. A. van Blitterswijk, K. de Groot, Biomaterials 2005, 26, 23.

[49] N. A. Sims, J. M. Quinn, Bonekey Rep. 2014, 3, 527.

[50] J. P. Moxham, Laryngoscope 2007, 117, 1790.

[51] R. Olivares-Navarrete, S. L. Hyzy, D. L. Hutton, G. R. Dunn, C. Appert, B. D. Boyan, Z. Schwartz, Acta Biomater. 2011, 7, 2740.

[52] D. J. Sieg, C. R. Hauck, D. Ilic, C. K. Klingbeil, E. Schaefer, C. H. Damsky, D. D. Schlaepfer, Nat. Cell Biol. 2000, 2, 249.

[53] D. J. Webb, K. Donais, L. A. Whitmore, S. M. Thomas, C. E. Turner, J. T. Parsons, A. F. Horwitz, Nat. Cell Biol. 2004, 6, 154.

[54] T. B. Deramaudt, D. Dujardin, F. Noulet, S. Martin, R. Vauchelles, K. Takeda, P. Rondé, PLoS One 2014, 9, e92059.

[55] Z. Yin, A. Sadok, H. Sailem, A. McCarthy, X. Xia, F. Li, M. A. Garcia, L. Evans, A. R. Barr, N. Perrimon, C. J. Marshall, S. T. Wong, C. Bakal, Nat. Cell Biol. 2013, 15, 860.

[56] Y.-R. V. Shih, Y. Hwang, A. Phadke, H. Kang, N. S. Hwang, E. J. Caro, S. Nguyen, M. Siu, E. A. Theodorakis, N. C. Gianneschi,
www.MaterialsViews.com

K. S. Vecchio, S. Chien, O. K. Lee, S. Varghese, in Proc. National Academy Sciences 2014 January 6, 2014.

[57] G. R. Beck, J. Cell. Biochem. 2003, 90, 234

[58] G. R. Beck Jr., E. Moran, N. Knecht, Exp. Cell Res. 2003, 288, 288.

[59] A. Hoppe, N. S. Güldal, A. R. Boccaccini, Biomaterials 2011, 32, 2757.

[60] Y. C. Chai, S. J. Roberts, J. Schrooten, F. P. Luyten, Tissue Eng. Part A 2011,0 , null.

[61] S. Aerts, D. Lambrechts, S. Maity, P. Van Loo, B. Coessens, F. De Smet, L.-C. Tranchevent, B. De Moor, P. Marynen, B. Hassan, P. Carmeliet, Y. Moreau, Nat. Biotechnol. 2006, 24, 537.

[62] R. C. Gentleman, V. J. Carey, D. M. Bates, B. Bolstad, M. Dettling, S. Dudoit, B. Ellis, L. Gautier, Y. Ge, J. Gentry, K. Hornik, T. Hothorn, W. Huber, S. Iacus, R. Irizarry, F. Leisch, C. Li, M. Maechler, A. J. Rossini, G. Sawitzki, C. Smith, G. Smyth, L. Tierney, J. Y. Yang, J. Zhang, Genome Biol. 2004, 5, R80. 